\title{
Design and simulation of a fast DC recharging station for EV
}

\author{
V. Castiglia*, P. Livreri*, R. Miceli*, IEEE, Member, F. Ricco Galluzzo**, G. Santelia* and G. Schettino* \\ *Dipartimento di Energia, Ingegneria dell'informazione e Modelli Matematici (DEIM) Università degli Studi di Palermo \\ Palermo, Italy; **Istituto per la Microelettronica e Microsistemi - Consiglio Nazionale delle Ricerche, Zona Industriale, Ottava Strada n. \\ 5, 95121 Catania, Italy; Dipartimento di Fisica e Astronomia, Università di Catania, Via S. Sofia, 64, 95123, Catania, Italy \\ email:vincenzo.castiglia@unipa.it,patrizia.livreri@unipa.it,rosario.miceli@unipa.it,fabiorg83@gmail.com, \\ G.santelia@gmail.com, giuseppe.schettino@unipa.it
}

\begin{abstract}
In this paper a detailed description of the design and simulation of a DC ultra-fast recharging station for Electric Vehicles is carried out. The system consist of a single AC/DC grid connected inverter, a DC-Bus and two DC/DC converter to recharge the batteries of the EVs. The system also has the vehicleto-grid (V2G) capability. The design of the components of the system and the control schemes are explained and a simulation of the system, performed in Matlab/Simulink environment is presented.
\end{abstract}

Index Terms-electric vehicles, $\mathrm{EV}$, fast DC battery charging, bi-directional power converter,vehicle-to-grid,V2G.

\section{INTRODUCTION}

Electricity distribution networks in the future will be called upon to meet consumer energy needs in terms of flexibility, cost-effectiveness, efficiency and reliability, enabling them to interact real-time with the network and benefit from market liberalization, by the participation of new producers and the development of new technologies. This implies that the distribution grid, now conceived, basically, as a passive structure to convey to consumers the power delivered by large generators connected to the transmission network, evolves towards an active network model [1].

According to the Smart Grids European Technology Platform, the Smart Grid, which is the vision and strategy for the future network, is an electrical network that can intelligently integrate the actions of all connected users (producers, consumers or prosumers) to distribute energy efficiently, sustainably, economically advantageously and reliably. Smart Grid requires the use of innovative products, components, innovative services and intelligent monitoring, control, communication, autohealing technologies.

The use of Smart Grid offers consumers a variety of opportunities to save on electricity costs, such as reducing consumption by redeploying the use of home appliances over the day, based on the cost of energy. Other incentives can come from the use of electric vehicles as a tool for storing electricity. Owners of an electric vehicle can be paid to enter network power at peak times, through the V2G (Vehicle to Grid) mode, or to absorb excess power at low demand moments [2], [3], [4].

\section{DESIGN OF THE FAST DC CHARGING STATION}

\section{A. Project specifications}

The proposed charging system model has been designed for ultra-fast DC charging of multiple electric vehicles, which can be implemented in parking areas located within shopping centers or companies. To carry out this type of recharging, it is necessary to use components capable of working with high voltage and current, characterized by considerable dimensions. For this reason, ultra-fast charging systems are located outside the vehicle (off-board). These systems have two advantages: they reduce the recharging time and they save space on vehicles, which can be used to use more powerful batteries. The charging station to be designed is made up of a single AC-DC converter connected to the mains and to a DC bus to which the electric vehicles are powered through a DCDC converter located inside of each charging column. To ensure the Vehicle to Grid (V2G) operation, the power flow inversion is needed and so all the converters are bi-directional. To limit the distortion in the voltage and current waveforms, an LCL filter was inserted between the AC-DC converter and the network.

The SAE j1772 standard defines 3 possible levels for fast DC charging: DC Level 1 200/450 V, 80 A, up to $36 \mathrm{~kW}$; DC Level 2 200/450 V, 200 A, up to 90 kW; DC Level 3 200/600 $\mathrm{V}, 400 \mathrm{~A}$, up to $240 \mathrm{~kW}$ [5]. For this work, the DC Level 2 (400 V, $200 \mathrm{~A})$ standard has been chosen.

The charging system consists of 2 DC charging columns, connected via a DC bus to an AC-DC converter. This system, therefore, allows the simultaneous charging of 2 electric vehicles with the possibility for vehicles to provide power to the grid in $\mathrm{V} 2 \mathrm{G}$ mode or, if not possible, to provide power to other vehicles connected to the columns in charging mode. This latter solution reduces the energy extracted from the grid. The charging station has been designed considering the worst case scenario, that is, when all vehicles are connected in fast charging mode with maximum voltage and current. Therefore, in this case each vehicle absorbs from the grid a power equal to [6]:

$$
P_{E V}=V_{\max } I_{\max }=400 * 200=80 \mathrm{~kW}
$$

The apparent power of the charging station can be calculated according to the following equation: 
Table I

BATTERY PARAMETERS

\begin{tabular}{cc}
\hline Technology & Lithium-Ion \\
\hline Nominal Voltage $V_{n}$ & $330 \mathrm{~V}$ \\
\hline Nominal capacity & $40 \mathrm{Ah}$ \\
\hline Open circuit voltage $V_{n, \max }$ & $386 \mathrm{~V}$ \\
\hline Internal resistance $R_{i}$ & $0.07 \Omega$ \\
\hline Cut-out voltage $V_{n, \min }$ & $225 \mathrm{~V}$ \\
\hline Recharging characteristic & $\mathrm{CC}-\mathrm{CV}$ \\
\hline
\end{tabular}

$$
A=\frac{k_{\text {load }} N_{r} P_{E V}}{\cos \phi}=\frac{1.1 \cdot 2 \cdot 80000}{0.95}=185.26 \mathrm{kVA}
$$

where:

- $k_{\text {load }}$ take into account the possible overcharge during transient, assumed equal to 1.1 ;

- $N_{r}$ number of the recharging stations;

- $\cos \phi$ it's the power factor, assumed equal to 0.95 .

The nominal apparent power of the fast DC recharging station is chosen equal to:

$$
A_{n}=200 \mathrm{kVA}
$$

The choice of the switching frequency of converters has been made taking into account some important aspects:

- reduced switching frequencies allow for less switching losses;

- high switching frequencies reduce the capacitor and inductor sizing used as filters.

- increasing the switching frequency increases the time required to simulate the system.

For these reasons, a switching frequency ranging from the low frequency range typically used is $5000 \mathrm{~Hz}$.

The low-pass filters, connected at the output of the DC-DC converters, will be designed to meet the following voltage and current ripple limits:

- voltage peak-peak ripple less than $2 \%$ of the DC component;

- current peak-pek ripple less than $10 \%$ of the DC component.

The LCL filter connected to he AC side of the inverter has been designed to meet the following characteristics:

- current THD less than $5 \%$;

- ripple attenuation factor less than $20 \%$.

The batteries used for the simulation have the features reported in Table I. Considering the maximum recharging current, the maximum voltage across the battery is:

$$
V_{b a t, \max }=V_{n, \max }+R_{i} I_{\max }=386+0.07 \cdot 200=400 \mathrm{~V}
$$

The charging station has to be connected to the grid in medium voltage, due to the high power demand. A MT/bt transformer, wich parameters are reported in Table II, is used.
Table II

TRANFORMER PARAMETERS

\begin{tabular}{cc}
\hline Primary voltage $V_{\text {grid }}$ & $20 \mathrm{kV}$ \\
\hline Secondary voltage & $400 \mathrm{~V}$ \\
\hline Frequency & $50 \mathrm{~Hz}$ \\
\hline Winding connection & $\mathrm{D} 11 / \mathrm{Yg}$ \\
\hline
\end{tabular}

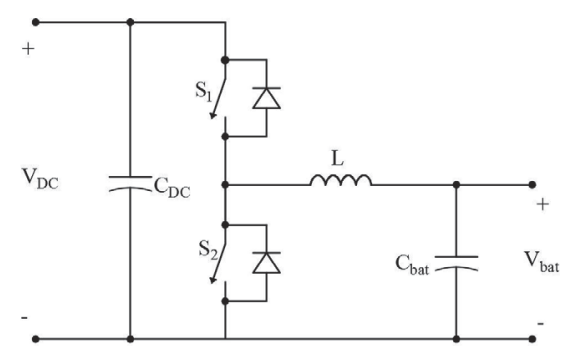

Figure 1. Half-bridge DC/DC converter

\section{B. DC/DC converter sizing}

DC-DC converters have the primary task of regulating current and voltage values appropriately for recharging the battery. To do this, switching converters are used, ie circuits using solid state devices (IGBT, MOSFETs, etc.) The topology used in this work is the half-bridge DC/DC converter shown in Fig.1. This topology can operate both in buck mode, powering the battery with an adjustable voltage lower than the input voltage (VDC), and in boost mode, providing an adjustable voltage input greater than that of the battery [7], [8].

In buck mode mode, the static switch $\mathrm{S} 1$ is controlled by the PWM technique, while the S2 switch is controlled complimentary to S1. From the circuit of Fig. 1 it can be noted that, when switch S1 is closed and S2 is open, the lower diode is reverse polarized and the current flows on the inductor, which stores electromagnetic energy. Subsequently, when the $\mathrm{S} 1$ switch is open, the upper diode is reverse polarized and the lower conducts the current due to the electromagnetic energy stored in the inductor, which has a decreasing trend over time.

Considering the CCM (Continuos Conduction Mode) operation of the converter, the inductance $\mathrm{L}$ and capacitance $\mathrm{C}_{\text {bat }}$ values can be chosen as explained in the following.

To obtain the minum value of the inductance $L$, the bound between the continuous conduction mode and the discontinuous conduction mode is considered. In this case, the ripple current can be expressed as:

$$
\begin{gathered}
\Delta I=\frac{1}{L} \int_{0}^{t_{o n}} v_{L} d t=\frac{V_{D C}-V_{n, \min }}{L} t_{o n}= \\
=\frac{V_{D C}-V_{n, \min }}{L} \frac{V_{n, \min }}{V_{D C} \cdot f_{s}}
\end{gathered}
$$

Rearraging eq. 1 , and imposing $10 \%$ ripple of the maximum current:

$$
L<\frac{V_{D C}-V_{n, \min }}{0,1 \cdot I_{\max }} \frac{V_{n, \min }}{V_{D C} \cdot f_{s}} \Rightarrow L<1.7 \mathrm{mH}
$$


Table III

DC/AC CONVERTER PARAMETERS

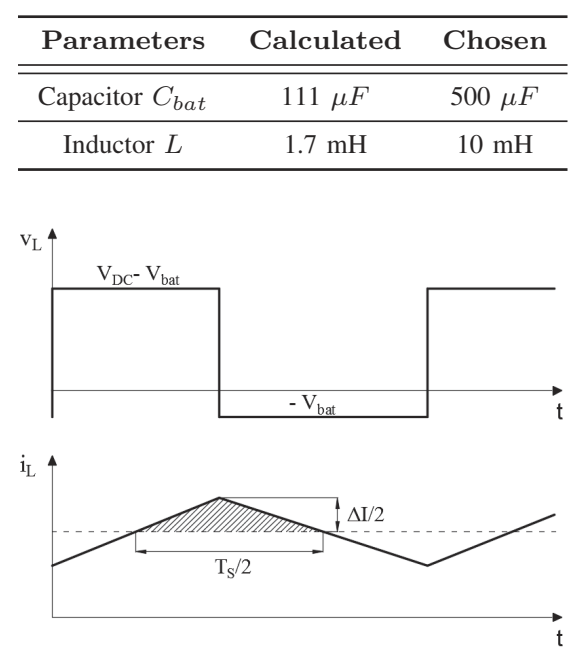

Figure 2. Current ripple

To obtain the value of the capacitance $C_{b a t}$, it can be supposed that the $i_{L}$ ripple current flows completely through the capacitor and the mean value of $i_{L}$ flows through the battery. The dotted area in Fig. 2 correspond to an additional charge $\Delta Q$. The peak-peak voltage ripple on the battery can be expressed as:

$$
\Delta V_{b a t}=\frac{\Delta Q}{C_{b a t}}=\frac{1}{C_{b a t}} \frac{1}{2} \frac{\Delta I \cdot T_{S}}{2 \cdot 2}
$$

By rearranging eq. 3 and considering the worst case, wich considers the maximum ripple current and the minimum battery voltage, the capacitance results:

$$
C_{b a t}>\frac{\Delta I \cdot T_{S}}{8 \Delta V_{b a t}} \Rightarrow C_{b a t}>111 \mu F
$$

Table IIIsummarizes the calculated values of the converter parameters and the chosen values according to eq. 2 and 4 .

\section{DC Bus capacitor sizing}

The DC bus stability depends directly on the size of the capacitor. The latter must stand the ripple of the DC curremt, and also maintain the voltagewithin certain intervals during transients. To size this capacitor, the following ranges of variation of nominal active power and DC bus voltage during transients were considered : $\Delta P_{n}=10 \%, \Delta V_{D C}=20 \%$.

The energy stored in the capacitor can be expressed as:

$$
E_{c}=\frac{1}{2} C_{D C}\left(\Delta V_{D C} \cdot V_{D C}\right)^{2}
$$

where:

- $E_{c}[\mathrm{~J}]$ is the energy stored in the DC-bus capacitor;

- $C_{D C}[\mathrm{~F}]$ is the capacitance of the DC-bus capacitor;

From the variation of the active power it can be obtained the energy that is exchanged during the transients:

$$
E_{s}=P_{n} \Delta P_{n} \cdot n \cdot T=A_{n} \cdot \cos \phi \cdot \Delta P_{n} \cdot n \cdot T
$$

where:

- $E_{s}[\mathrm{~J}]$ is the energy exhanged during the transient of the system;

- $P_{n}[\mathrm{~W}]$ is the nominal active power of the system;

- T [s] it's the period of the AC waveform;

- $\mathrm{n}$ is a multiple of the period $\mathrm{T}$, assumed equal to 0.5.

In order for the condenser to maintain DC bus voltage within the limits set, it must be:

$$
\begin{aligned}
E_{c} & =E_{s} \\
\frac{1}{2} C_{D C}\left(\Delta V_{D C} \cdot V_{D C}\right)^{2} & =A_{n} \cdot \cos \phi \cdot \Delta P_{n} \cdot n \cdot T
\end{aligned}
$$

Rearranging eq. the DC-Bus capacitance results:

$$
C_{D C}=\frac{2 A_{n} \cdot \cos \phi \cdot \Delta P_{n} \cdot n \cdot T}{\left(\Delta V_{D C} \cdot V_{D C}\right)^{2}} \Rightarrow C_{D C}=47 m F
$$

\section{LCL filter sizing}

A three-phase LCL filter is inserted between the AC-DC converter and the transformer, as shown in Fig. 3. This filter has the task of reducing the high-order harmonics on the grid side. If the sizing is not optimalit can cause a lower attenuation than expected or even cause an increase in distortion. Current harmonics can cause inductor saturation or filter resonance.

The choice of inverter side inductors depends on several factors, such as DC bus voltage, inverter modulation index, switching frequency and Total Harmonic Distortion (THD). While the size of capacitors and grid side inductors is conditioned by grid parameters, reactive power, resonance frequency, and Ripple Attenuation Factor (RAF). Before choosing the filter parameters, the following parameters have to be defined:

$$
\begin{gathered}
Z_{b}=\frac{\left(V_{n, b t}\right)^{2}}{A_{n}} \\
C_{b}=\frac{1}{\omega_{n} Z_{b}} \\
L_{b}=\frac{Z_{b}}{\omega_{n}}
\end{gathered}
$$

where:

- $Z_{b}[\Omega]$ is the base impedance of the system;

- $V_{n, b t}[\mathrm{~V}]$ is the rms value of the transformer secondary voltage;

- $A_{n}$ [VA] is the nominal apparent power of the system;

- $C_{b}[\mathrm{~F}]$ is the base capacitance of the system;

- $\omega_{n}[\mathrm{red} / \mathrm{s}]$ is the nominal angluar frequency of the system;

- $L_{b}[\mathrm{H}]$ is the base inductance of the system

The filter capacitance is designed based on the reactive power at the fundamental frequency supplied to the capacitors. Generally, the reactive power absorbed by the filter capacitor must be less than $5 \%$ of the nominal power of the AC-DC converter. For this reason it is possible to choose the capacitance in the filter as [9], [10] :

$$
C_{f} \leq 0.05 \cdot C_{b}=\frac{0.05}{\omega_{n} Z_{b}}=\frac{0.05 \cdot A_{n}}{2 \pi f_{n}\left(V_{n, b t}\right)^{2}}
$$




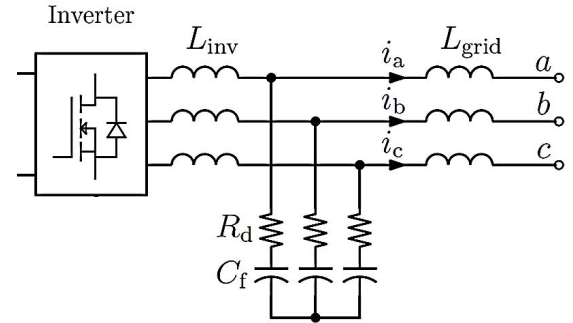

Figure 3. Three-phase LCL filter

For the sizing of the converter side inductors, the THD of the current is set to be less than $5 \%$. The value of the inductance can be determined by considering the following equation:

$$
\begin{aligned}
& L_{i n v}=\frac{f_{n}}{f_{b}} \cdot \frac{L_{b}}{T H D_{i}} \sqrt{\frac{\pi^{2}}{18}\left(\frac{3}{2}-\frac{4 \sqrt{3}}{\pi} \cdot m_{a}+\frac{9}{8} m_{a}^{2}\right)}= \\
& =\frac{\left(V_{n, b t}\right)^{2}}{A_{n} \cdot T H D_{i} \cdot 2 \pi \cdot f_{s}} \sqrt{\frac{\pi^{2}}{18}\left(\frac{3}{2}-\frac{4 \sqrt{3}}{\pi} \cdot m_{a}+\frac{9}{8} m_{a}^{2}\right)}
\end{aligned}
$$

where:

- $f_{s}[\mathrm{~Hz}]$ is the switching frequency;

- $T H D_{i}$ is the current total harmonic distortion;

- $m_{a}$ is the modulation index of the inverter.

For the sizing of the grid size inductor, chosing a Ripple Attenuation Factor (RAF) equal to $20 \%$, the value of the inductance can be calculated with the following equation:

$$
L_{\text {grid }}=\frac{R A F+1}{R A F \cdot C_{f} \cdot \omega_{s}^{2}}
$$

Applying eq. 5, 6, 7 to the proposed system, $C_{f}, L_{i n v}$ and $L_{\text {grid }}$ can be calculated.

The resonance frequency of the LCL filter has to be calculated to verify that is inclueded between 10 times the grid frequency and a half of the switching frequency.

$$
\begin{aligned}
& f_{\text {ris }}=\frac{1}{2 \pi} \sqrt{\frac{L_{\text {inv }}+L_{\text {grid }}}{L_{\text {inv }} \cdot L_{\text {grid }} \cdot C_{f}}} \Rightarrow f_{\text {ris }}=669 \mathrm{~Hz} \\
& 10 * f_{\text {grid }}<f_{\text {ris }}<\frac{f_{s}}{2} \Rightarrow 500<669<2500 \mathrm{~Hz}
\end{aligned}
$$

The capacitors have also a series damping resistor, wich values is:

$$
R_{d}=\frac{1}{3 \cdot C_{f} \cdot 2 \pi f_{r i s}} \Rightarrow R_{d}=1,31 \Omega
$$

Table IV summarize the calculated LCL filter parameters, and the chosen values for the simulation.
Table IV

FILTER PARAMETERS

\begin{tabular}{ccc}
\hline Parameters & Calculated & Chosen \\
\hline \hline Filter Capacitor $C_{f}$ & $995 \mu F$ & $200 \mu \mathrm{F}$ \\
\hline Inverter side inductor $L_{i n v}$ & $0.48 \mathrm{mH}$ & $0.5 \mathrm{mH}$ \\
\hline Grid side inductor $L_{g r i d}$ & $0.69 \mathrm{mH}$ & $0.7 \mathrm{mH}$ \\
\hline Damping resistor $R_{d}$ & $1.31 \Omega$ & $1.5 \Omega$ \\
\hline
\end{tabular}

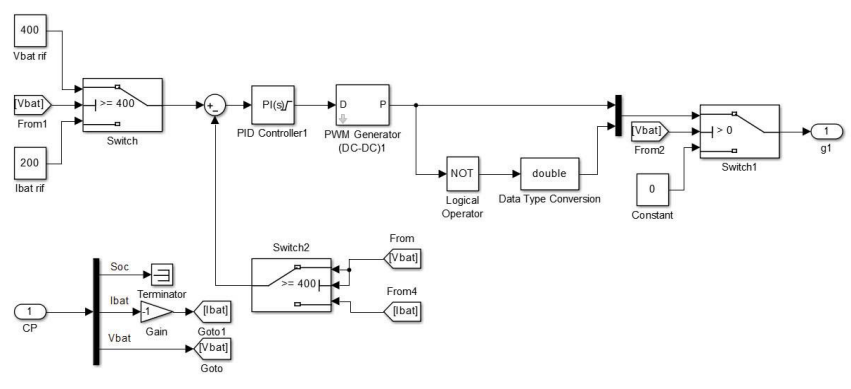

Figure 4. DC/DC converter control system

\section{DC/DC AND AC/DC CONVERTER CONTROL SYSTEMS}

\section{A. DC/DC converter control system}

Each DC-DC converter is connected to a charge control system, shown in Fig. 4.

As reported in Table I, the simulated batteries are of the Lithium-Ion type and need a Constan Current - Constant Voltage (CC-CV) charger. The control system must operate a constant current control when the battery voltage is lower than the maximum value of $400 \mathrm{~V}$, and then maintain this voltage until the current tends to set to zero. In order to perform this control, proportional and integral (PI) controllers have been used, which receive the difference between the reference signal and the real signal input, and provide the control signal, that is, the duty cycle.

For both charging modes, constant current and constant voltage, a single PI regulator was used calibrated with the proportional coefficient $K_{p}$ and integral action $K_{i}$ reported in Table V.

\section{B. DC/AC converter Control system}

In order to keep the DC-bus voltage constant, the DC/AC inverter need an appropriate control system, shown ing Fig. 5.

In this system, the control action is generated from the transformation in $d q$-Frame, which returns the magnitudes of a three-phase system to the equivalent ones referring to a two-phase coordinate system rotating at the synchronous rate. Thanks to the transformation of the coordinates, the $\mathrm{AC}$

Table V

DC/DC PI REGULATORS COEFFICIENTS

\begin{tabular}{cc}
\hline Proportional Gain $K_{p}$ & 0.5 \\
\hline Integral Gain $K_{i}$ & 4 \\
\hline
\end{tabular}




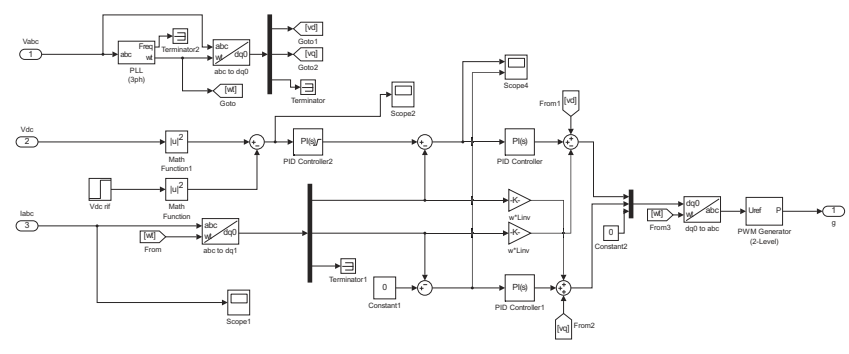

Figure 5. DC/AC converter control system

Table VI

DC/AC PI REGULATORS COEFFICIENTS

\begin{tabular}{ccc}
\cline { 2 - 3 } & Current PI & Voltage PI \\
\hline Proportional Gain $K_{p}$ & 5 & 0.004 \\
\hline Integral Gain $K_{i}$ & 500 & 0.2 \\
\hline
\end{tabular}

current of the converter can be controlled by the traditional PI, otherwise it is ineffective to manipulate alternating current quantities. Fig. 5 shows the scheme of the control system in which the two components of the current have been decoupled.

Such decoupling makes the two current regulation channels independent . Any transient phenomenon occurring on one channel does not reflect on the other. By decoupling the two channels, it is also possible to adjust the flow of the active power by intervening on the direct current component and that of the reactive power by acting on the quadrature component of the current. In the simulation, a null value was set as reference for the $i_{q}$ component so as to undo reactive power exchanges with the grid. The reference of the direct current component $i_{d}$, that is, the reference of the active power, is generated by the DC bus voltage control system. The voltage control system on the DC bus acts on the square of the voltage signals, making the controller faster and reducing the duration of transients [13].

The PI regulators in the current channels and the PI regulator in the DC-Bus voltage control have the coefficient reported in Table VI. To allow parallel operation of the inverter with the grid, the control system must hook up the frequency and phase of the mains voltage. The module and phase hooking takes place via the "PLL" (Phase Locked Loop) Matlab block.

\section{Simulation RESUlts}

A simulation of the system has been carried out to verify the correct operation of the fast DC recharge and the Vehicle to Grid (V2G) features. The input values for this simulation are summarized in Table VII.

Fig. 6 depicts the state of charge, current and voltage measured on the two electric vehicles batteres.

It can be seen how the SoC for vehicle 1 starts to grow at $=$ $0.2 \mathrm{~s}$, when the vehicle is connected to charging station. The current of EV1 goes from zero to the maximum value imposed by the control system for ultra-fast charging. This increase in current causes a sudden increase in the voltage measured at the battery. As soon as the current reaches its maximum value,
Table VII

INPUT VALUES FOR THE FIRST SIMULATION

\begin{tabular}{ccc}
\hline & EV 1 & EV 2 \\
\hline \hline Initial State of Charge & $50 \%$ & $70 \%$ \\
\hline Time of connection & $0.2 \mathrm{~s}$ & $0.5 \mathrm{~s}$ \\
\hline Reference Current & $200 \mathrm{~A}$ & $-200 \mathrm{~A}$ \\
\hline Mode of peration & Fast DC recharge & V2G \\
\hline
\end{tabular}
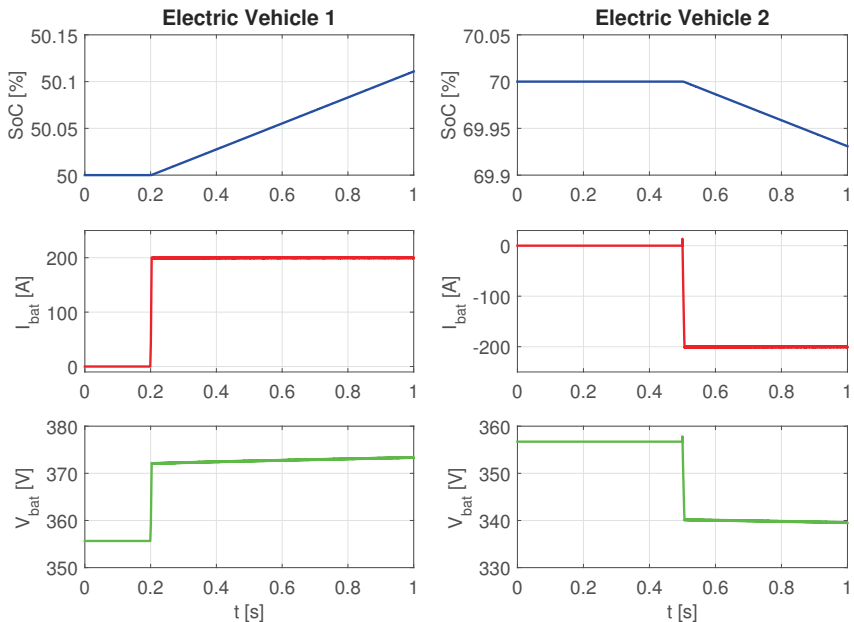

Figure 6. State of charge, current and voltage trends on the batteries of EV1 and EV2

the battery voltage continues to grow slower and depending on the state of charge.

The EV2 is connected in V2G mode at $\mathrm{t}=0.5 \mathrm{~s}$, and its SoC starts to decrease. Compared to EV1, the EV2 current is negative and it is flowing from the battery to the recharging system. This lead to a sudden drop on the battery voltage, that continue to decrease depending on the state of charge.

Fig. 7 shows the voltage and the current ripple on the battery of EV1. It can be seen that the peak to peak ripple limits are largely respected:

$$
\begin{gathered}
\Delta I_{\text {bat }}<10 \% \cdot I_{\text {max }} \Rightarrow 2 A<20 A \\
\Delta V_{b a t}<2 \% \cdot V_{\text {bat }, \text { max }} \Rightarrow 0.2 \mathrm{~V}<8 \mathrm{~V}
\end{gathered}
$$

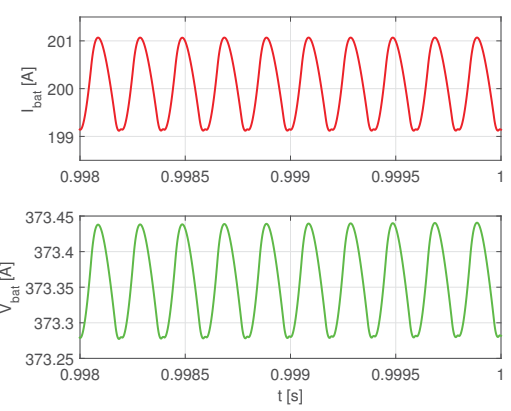

Figure 7. Voltage and current ripple on the battery 


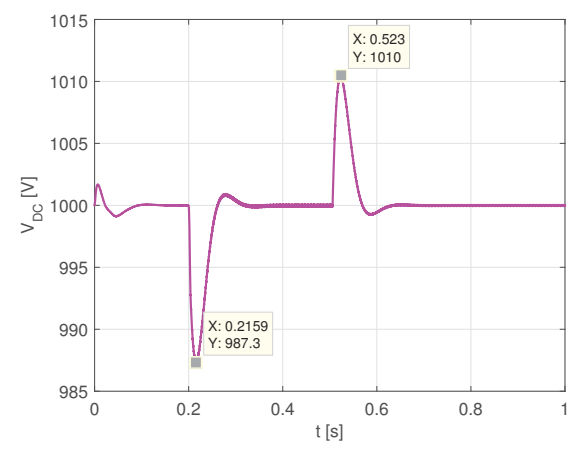

Figure 8. DC-Bus voltage

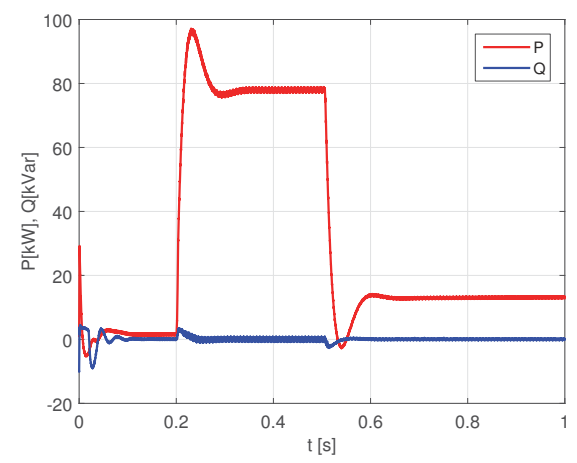

Figure 9. Active and reactive power trends in the low voltage side of the transformer

Fig. 8 shows the trend of the DC-Bus voltage. At $t=0.2 \mathrm{~s}$, when EV1 is connected, the voltage start to decrease due to the power request. The $\mathrm{DC} / \mathrm{AC}$ control system reacts by regulating the voltage to the reference value. At $\mathrm{t}=0.5 \mathrm{~s}$, when $\mathrm{EV} 2$ is connected in V2G mode, the DC-Bus voltage start to increase due to the power input. In both transients, voltage is regulated in less than 0.15 seconds with overshot and undershot of less than 15 volts. The project specification for the DC-Bus voltage variation is widely respected:

$$
\Delta V_{D C}<20 \% V_{D C} \Rightarrow 15 \mathrm{~V}<200 \mathrm{~V}
$$

Fig. 9 shows the trend of the active and reactive power supply by the grid and measured in the low voltage side of the transformer. Before connecting the vehicles, the grid supplies some power due to the loss on the system components. At $\mathrm{t}=0.2 \mathrm{~s}$, after a short transient, the active power equals the power requested from EV1 summed to the loss of the system. At $\mathrm{t}=0.5 \mathrm{~s}$, when EV2 is connected in V2G mode, it can be seen that the power supplied by the grid drastically decreases, limiting the impact of the recharging station on the elecric power distribution system. The reactive power is retained zero by the control system during the different operating conditions.

\section{CONCLuSions}

In this paper, a recharging system for electric vehicles has been designed and simulated, characterized by the ability to perform ultra-fast recharges, so that battery recharging is completed in less than one hour. It also has the ability to reverse the direction of the power flow so that the vehicle can operate in V2G (Vehicle to Grid) mode. It has therefore been seen that once the electric vehicle is connected to the charging system, it can provides auxiliary services to the electric power distribution grid.

\section{ACKNOWLEDGMENTS}

This work was financially supported by PON03PE_00214_1/7 TECLA - Ricercatori ed Esperti di Alta tecnologica e Innovazione Tecnologica Applicata al Settore dei Beni Culturali - (CUP B79G14001460007) and by SDESLab (Sustainable Development and Energy Saving Laboratory) of the University of Palermo.

\section{REFERENCES}

[1] Miceli, R. Energy management and smart grids (2013) Energies, 6 (4), pp. 2262-2290, DOI: 10.3390/en6042262.

[2] Yiyun T., Can L., Lin C., Lin L., "Research on Vehicle-to-grid Technology", International Conference on Computer Distributed Control and Intelligent Environmental Monitoring, pp. 1013-1016, 2011.

[3] Habib S., Kamran M., Rashid U., "Impact analysis of vehicle-to-grid technology and charging strategies of electric vehicles on distribution networks - A review", Journal of Power Sources, vol. 227, pp. 205214, March 2015.

[4] Yilmaz M., Krein P. T., "Review of the Impact of Vehicle-to-grid Technologies on Distribution Systems and Utility Interfaces", IEEE Transactions on Power Electronics, vol. 28, no. 12, December 2013.

[5] http://www.sae.org/smartgrid/chargingspeeds.pdf

[6] Arancibia A., Strunz K., "Modeling of an Electric Vehicle Charging Station for Fast DC Charging", IEEE International Electric Vehicle Conference, pp. 1-6, 2012.

[7] Tytelmaier K., Husev O., Veligorskyi O., Yershov R., "A Review of Non-Isolated Bidirectional DC-DC Converters for Energy Storage Systems", International Young Scientists Forum on Applied Physics and Engineering, pp. 22-28, 2016.

[8] Du Y., Zhou X., Bai S., Lukic S., Huang A., "Review of Non-isolated Bi-directional DC-DC Converters for Plug-in Hybrid Electric Vehicle Charge Station Application at Municipal Parking Decks", Applied Power Electronics Conference and Exposition (APEC), Twenty-Fifth Annual IEEE, pp. 1145-1151, 2010.

[9] Park M. Y., Chi M. H., Park J. H., Kim H. G., Chun T. W., Nho E. C., "LCL - filter Design for Grid-Connected PCS Using Total Harmonic Distortion and Ripple Attenuation Factor", International Power Electronics Conference (IPEC), pp. 1688-1694, 2010.

[10] Liserre M., Blaabjerg F., Hansen S., "Design and Control of an LCLFilter-Based Three-Phase Active Rectifier", IEEE Transactions on Industry Applications, vol. 41, no. 5, September/October 2005.

[11] Karlsson P., Svensson J., "DC Bus Voltage Control for a Distributed Power System", IEEE Transactions on Power Electronics, vol. 18, no. 6, November 2003.

[12] Blaabjerg F., Teodorescu R., Liserre M., Timbus A.V., "Overview of Control and Grid Synchronization for Distributed Power Generation Systems", IEEE Transaction on Power Electronics, vol. 53, no. 5, pp. 1398-1409, 2006.

[13] Mishra M. K., Karthikeyan K., "A Fast-Acting DC-Link Voltage Controller for Three-Phase DSTATCOM to Compensate AC and DC Loads", IEEE Transactions on Power Delivery, vol. 24, no. 4, 2009.

[14] Longo, M., Zaninelli, D., Viola, F., Romano, P., Miceli, R., Caruso, M., Pellitteri, F. Recharge stations: A review (2016) 2016 11th International Conference on Ecological Vehicles and Renewable Energies, EVER 2016, art. no. 7476390,DOI: 10.1109/EVER.2016.7476390.

[15] Caruso, M., Cecconi, V., Di Tommaso, A.O., Rocha, R. Sensorless variable speed single-phase induction motor drive system based on direct rotor flux orientation (2012) Proceedings - 2012 20th International Conference on Electrical Machines, ICEM 2012, art. no. 6350007, pp. 1062-1068, DOI: 10.1109/ICEIMach.2012.6350007.

[16] Caruso, M., Cecconi, V., Di Tommaso, A.O., Rocha, R. A rotor flux and speed observer for sensorless single-phase induction motor applications (2012) International Journal of Rotating Machinery, 2012, art. no. 276906,DOI: 10.1155/2012/276906.

[17] Caruso, M., Di Tommaso, A.O., Genduso, F., Miceli, R. Experimental investigation on high efficiency real-time control algorithms for IPMSMs (2014) 3rd International Conference on Renewable Energy Research and Applications, ICRERA 2014, art. no. 7016531, pp. 974-979. 